\title{
Parks and Recreation
}

\author{
Planning the Epistemic Community
}

Information produced according to the conventional model, by presumably neutral experts who work outside and apart from the political and bureaucratic process through which policy gets made, does not become embedded in the institutions or the players' understandings. It will become ... shared knowledge, only if there is plenty of talk about the meaning of the information, its accuracy, and its implications. Information does not influence unless it represents a socially constructed and shared understanding created in the community of policy actors. If, however, the meaning does emerge through such a social process, the information changes the actors and their actions, often without their applying it expressly to a specific decision. -Judith Innes (1998, 56)

No one achieves anything alone.

-Leslie Knope, character on the NBC TV series

Parks and Recreation

There is a joke sometimes told in urban planning circles, involving how many planners it takes to screw in a light bulb. The answer? None, but it takes fifteen to prepare the plan for coping in the dark. Or, sometimes: None, they are all too busy trying to plan the perfect light bulb. Strikingly, both answers are "none," and both capture the essence of what is often the common picture of urban planners in American cities: wellmeaning professional experts with detailed knowledge and technical expertise, producing beautiful urban plans that all too often end up 
irrelevant, ignored, or distorted in the messy political and marketdriven processes that fundamentally drive urban development.

Indeed, planners themselves often lament the problems created from the largely unplanned market-driven urban sprawl that characterizes most US cities, and historical studies of metropolitan development patterns rarely point to deliberate urban planning as a prominent factor in shaping regional growth. This is not to suggest that politics and policy aren't important. To the contrary, there is a whole school of thought focused on the important role of urban growth coalitions in shaping regional development (Fulton 200I; Logan and Molotch 2007). Meanwhile, federal policies-everything from transportation spending to forms of housing subsidies and structures of local government-are critical for understanding how regions have grown (Lewis and Sprague I997; Muro et al. 2008).

But what is clearly inadequate is the sort of technocratic, dispassionate, and disconnected "rational planning" model which has often dominated the profession. Increasingly, planners are recognizing how much their work is embedded in the broader social and political processes that shape cities. Indeed, one perspective, which we turn to in chapter 6 to help us understand conflict and collaboration in regional development processes, argues that planners should play more of an advocacy role. According to this approach, planners should explicitly articulate their values in developing planning proposals, and do so while advocating for the interests of underrepresented perspectives and constituencies (Checkoway I994; Davidoff I965).

While this "advocacy planning" approach occupies one sort of extreme, other planning scholars have suggested that the planner's job is mainly to help build consensus in the planning process. This can be done through a combination of providing professional advice and analysis to elected officials and the public and mediating between conflicting interests to develop shared goals and priorities. While this "communicative rationality" approach is also a departure from the rational-planner perspective, it is less conflictual than the messy, tense, and combative processes envisioned in advocacy planning. Instead, communicative rationality emphasizes that the process by which information is produced is critically important in ensuring its understanding and use by institutions (Forester 1989; Innes and Booher 1999; Innes 1998).

Linkages between this perspective and what we are terming diverse and dynamic epistemic communities are not hard to find. As reflected in the quote from Judith Innes that begins this chapter, communicative 
planning recognizes that it is important to consider not just what planners and regional stakeholders know but who they know it with, and how information developed in shared processes actually shapes actors and their actions (versus information generated in separate processes of technocratic planning). At the same time, there are key distinctions between notions of communicative rationality and our perspectives on epistemic communities. First, in our view, an epistemic community can include conflict and skirmish that will raise uncomfortable but important issues; and second, planners playing a leading role in epistemic communities is only one variation on a theme-only one possible way to build an epistemic community.

This chapter is all about that variation. In two of our regional case studies, the role of formal collaborative regional planning emerged as an important institutional support for the development of diverse and dynamic epistemic communities. In Sacramento, these processes were driven primarily by the public sector through the efforts of the Sacramento Area Council of Governments (SACOG) to develop long-range regional plans through broad participatory processes. These processes helped a wide range of constituencies understand the importance of an integrated land-use and transportation planning process in ensuring quality of life in the region. Initiated in the early 2000s, this "Blueprint process" was prominent in the region's efforts to recover from the economic shocks of the I990s; it also revealed some underlying yet commonly held values around resource conservation and sustainability, helping bridge gaps between otherwise uncommon allies.

In Salt Lake City, in the midst of broadly held conservative and antigovernment sentiments, a very similar participatory process of longrange regional planning was led not by a regional government planning body but by a small nonprofit organization called Envision Utah. Despite different origins, the process of information sharing across diverse constituencies, and the generation of broadly shared goals for regional development patterns informed by like values across diverse constituencies, were quite similar to Sacramento's. Here, the inclusion of diverse constituencies in regional planning processes was (perhaps counterintuitively) also facilitated by certain characteristics of the Mormon Church and the implications they had for regional social norms.

In what follows, we look first at Salt Lake City and then Sacramento. In each case, we review the patterns of economic growth and social equity in the region, explore the processes that have brought together diverse epistemic communities, and consider how these processes have shaped patterns of growth and equity. In each case, we try to highlight the elements 


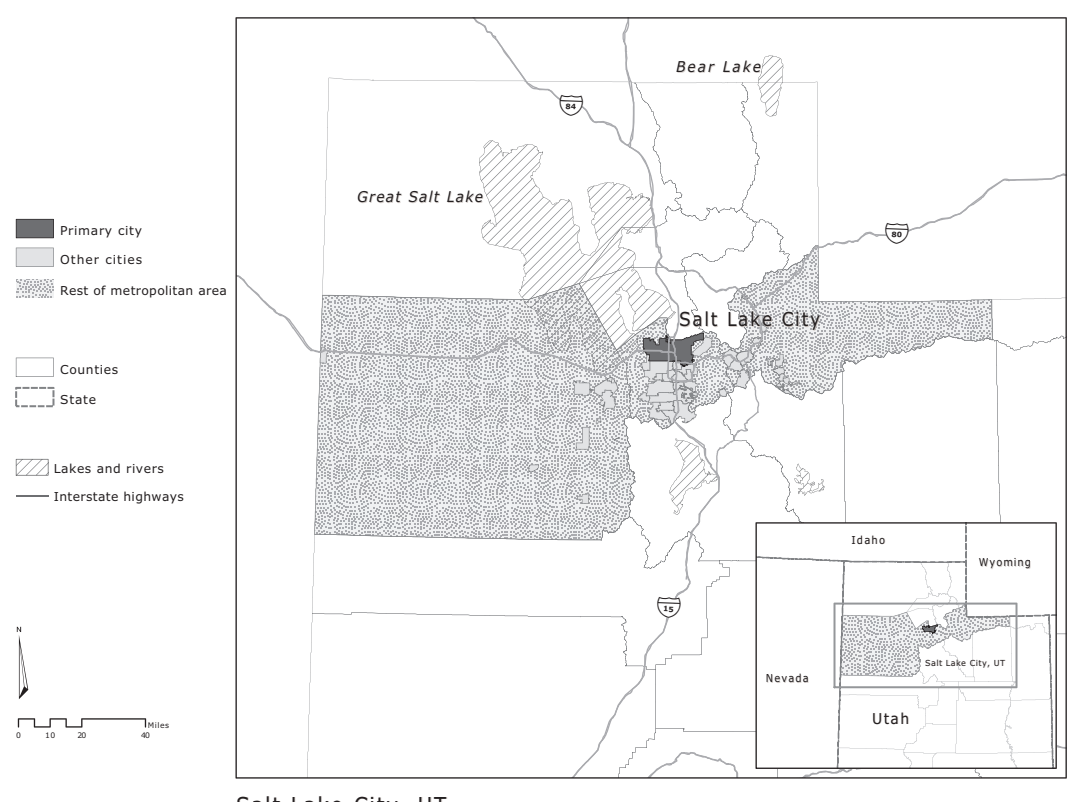

Salt Lake City, UT

MAP 4.I. Salt Lake City Region.

we raised in our framework in chapter I: membership in regional knowledge sharing; the ties that bind different constituencies together; the ways knowledge is generated and considered valid; the focus of particular outcomes; and the dynamics of knowledge creation and interpretation over time. We conclude the chapter with some further discussion of the overall characteristics of planning-influenced community-building, setting the stage for comparison with other approaches in the chapters that follow.

\section{SALT LAKE CITY}

Our team arrived for the Salt Lake City (map 4.I) case study in three waves. The first of us, a research analyst assisting on the project, came early to spend the weekend with family; the second (Chris Benner) arrived to get the interviews started; and the last (Manuel Pastor) slipped into town in the early evening and just in time for the second day. Greeting him at the airport was Robert Grow, president and CEO of Envision Utah; he was not only enthusastic about the research visit but also eager to show off the new light rail extension that would whisk both Grow and Pastor to downtown Salt Lake.

The pride was justified-it's a nice and efficient line-but the sense of accomplishment wasn't about the quality of the trains or the smoothness 
of the ride. In a conservative locale usually adverse to taxes and planning, the overall system had derived its local funding from an increase in the sales tax that was approved by a remarkable two-thirds of voters in 2006. One of the more significant contributions to this success was a savvy marketing campaign by the Utah Transit Authority. Centered on the fact that the system takes $8 \mathrm{I}, 000$ cars off the road every day and incorporating the tag-line "Even if you don't ride it, you use it," the campaign specifically marketed the benefits of transit to non-riders as well as riders. A multi-year planning effort also shifted hearts and minds, such that suburbanites who had once resisted further spending on light rail began to clamor to have lines extended to them. Most remarkable was the journey from the airport itself. Grow noted that the line was going through some of the poorest and most Hispanic neighborhoods in the city, suggested how the stations there would both promote local businesses and connect people to jobs, and then pointed out all the compact development occurring in and around the booming downtown.

The new light rail line, linking poor neighborhoods to employment opportunities while also serving the needs of elite air travelers, is a physical manifestation of the diverse membership in the region's knowledge networks. The lay clergy structure of the Church of Jesus Christ of Latter-day Saints (LDS Church) and its extensive welfare operations also contributes to these diverse connections, since it creates a systematic and personal connection between successful elites and the poor that is rare elsewhere in the country. Meanwhile, Envision Utah, a nonprofit founded in the mid-I990s, has helped the region address major growth challenges by bringing thousands of ordinary neighborhood residents together with regional business and public-sector leaders in a sustained effort of communicative planning.

To those who think that equity, growth, and sustainability must be the province of politically progressive locations, Salt Lake City might seem like an odd choice (although the central city has long had Democratic mayors, some with remarkably leftist politics). ${ }^{\mathrm{I}}$ But the value of a case-selection process driven at least partly by quantitative considerations is that it can yield pleasant (or at least interesting) surprises-as well as pleasant greetings and rides from the airport.

As it turns out, over the last three decades, Salt Lake City has maintained levels of inequality and poverty that remain substantially below national averages, while also creating an economic growth trajectory that is remarkable, not only in its consistent and sustained growth over a long period, but also in the relatively even distribution of that growth. 
This growth has been sustained even in the most recent decade, as the historically homogeneous Salt Lake City region has experienced a dramatic growth in its non-white population, which has put it on a path to become a "majority-minority" region several years before the country as a whole.

There are several structural factors that help explain this sustained growth, including high quality of life and relatively low housing costs, both of which have helped attract people and businesses to the region. There are also several structural factors that might explain the more inclusive nature of that growth, including an improving education profile for the metro (compared to the larger Western census region). However, our main object in this case is to examine how a diverse regional knowledge community has come together, how it relates to broader social processes and norms in the region, and how this might help explain the region's patterns of growth and equity.

Below, we begin by reviewing the statistical record. We then turn to the broader institutional and cultural influence of the Mormon Church, and specifically the way this facilitates connections between communities of prosperity and poverty. We then consider the role of Envision Utah, arguing that while the longer-term culture of the region paved the way for communicative planning, the planning itself was well executed and well suited to the specificities of the region, and played an important role in faciliating connections across diverse perspectives and constituencies.

\section{Sustained and Shared Prosperity}

Between I980 and 2010, employment in the Salt Lake metropolitan area grew by an explosive II 9 percent, compared to an average of 57 percent for the top I 92 metros in the United States and 73 percent for those in the West. Growth in average earnings per job was about average: 22 percent in real terms, roughly comparable to the I9-percent average for all top 192 metros and 20 percent for those in the West. What is remarkable is that the wage gains were distributed across all levels of the labor market. Between 1990 and 20I0, for instance, average real earnings in the third of two-digit NAICS industries paying the highest wages grew by 23 percent, while earnings grew by 24 percent in the middle third and 28 percent in the lowest third; most American metro regions experienced earnings growth only at the top, and often declining earnings in the lower tiers of the labor market. Salt Lake City also 
experienced almost equal growth in low-, medium-, and high-paying industries over this time, while most metro regions either experienced an expansion in low-wage industries or a polarization of employment, with growth in low-paying and high-paying industries but not in middleincome industries.

This stronger performance in the middle of the labor market is reflected in more traditional equity measures. Salt Lake's poverty rate indeed increased from 8.6 percent in 1980 to I3.I percent in $20 \mathrm{IO}$, but this still remained substantially below the I 5.6-percent average for the top I 92 metro areas. Inequality, as measured by the $80 / 20$ household income ratio, increased by 8.5 percent over the three decades (from 3.7 to 4 ), substantially less than the I 2 -percent average increase across the top 192 metros. The Gini coefficient of household income inequality in Salt Lake City in I980 was 0.37 , lower than the 0.39 for the United States as a whole. Though inequality worsened in subsequent decades, the Gini coefficient in Salt Lake remained among the lowest of the top I 92 metros ( 23 rd lowest, with neighboring Ogden-Clearfield and Provo-Orem metros ranked 2 nd and I 5 th lowest) and substantially below national averages.

The region's record in sustaining growth is also striking. The single longest unbroken growth spell of any metropolitan region between I 990 and $201 \mathrm{I}-\mathrm{a}$ period of 69 quarters (more than I7 years) of unbroken annualized growth in employment-is in Ogden, Utah, just north of Salt Lake City; while this is formally a different metropolitan area, the entire Wasatch Front urbanized area, stretching from Ogden in the north to Provo in the south, is considered by residents the more accurate functional metropolitan area and is the scale of regional planning addressed by Envision Utah. Both Salt Lake City and Provo experienced short employment downturns in the 2000 recession, but with each boasting unbroken growth spells that got to I0.5 years, they still rank in the top 20 percent of metropolitan areas in the country in the maximum length of sustained growth spells.

\section{The Book of Mormon}

What explains this pattern for growth and equity? First, it is impossible to talk about development in Salt Lake without acknowledging the profound influence of the Church of Latter Day Saints (LDS Church). Though the percentage of Utah's population that is Mormon has declined with population growth, statewide, it was still an estimated 
62 percent in 2012, and in Salt Lake County (the core of the CBSA) it was just over 5 I percent (Canham 20I2). Of course, the influence of the LDS Church goes beyond simply the percentage of the population, as it plays a substantial role in shaping the economics, politics, and culture of the region.

One of the important influences of the church has to do with its role in addressing poverty in the region. While Mormons are generally quite conservative and have a strong suspicion of centralized government programs-a sentiment embedded in the larger Utah culturethe church has developed a quite substantial internal welfare structure that was first established in the I930s. Mormons are encouraged to fast one day a month, and to donate at least the money that was saved on two missed meals, if not more, to the local church's welfare fund. One hundred percent of these fast offerings are used to provide assistance to those in need (adminstrative costs associated with these programs are privately provided by the church through other channels). The church owns hundreds of thousands of acres of farmland and dairy operations. Food, including processed food products largely manufactured by the LDS-owned Deseret Industries and Deseret Manufacturing, are sent to the over I 40 storehouses that the LDS Church operates. All told, some IO, O०० volunteers work in these enterprises each year and in a range of humanitarian assistance efforts, and the total amount of humanitarian assistance provided between I985 and 20 I I was estimated at $\$$ I.4 billion. ${ }^{2}$

The bishop of the local ward or congregation is responsible for identifying those in need and for providing assistance to help people get back on their feet. This involves not simply allocating access to food and financial support but also advice and referrals to a range of support services provided by the LDS Church, including employment services, English as a second language assistance, social services, and clothing distribution, among others.

This important role of the local bishop highlights another feature of the LDS Church structure which becomes particularly important for our analysis: the personal contact with those less fortunate. The LDS Church has a lay clergy structure at the local level; bishops are called to service from among the members of a local congregation and serve without pay for a temporary period, typically three to seven years. Men who are called to be bishops are frequently among the more prominent and successful leaders in the community, including major business leaders. ${ }^{3}$ Thus, as we were told by a number of our key informants, many business executives and CEOs in the region have direct experience for 
an extended period of time acting essentially as social workers. While most of the assistance provided through these internal welfare structures benefits Mormons, bishops also frequently provide assistance to non-Mormons, reflecting the church's commitment to helping those in need regardless of their beliefs.

The LDS Church has also contributed to a different tone around immigrant integration. This is partly because the church has such a significant international presence, but also because missionaries, who are mostly between the ages of eighteen and twenty-five, serve I 8-24 months abroad and acquire a knowledge of what it means to be a stranger in a strange land. Whatever the factors, the results have been remarkable for what is clearly a conservative state. In I999, immigrants were allowed to obtain driver's licenses using a tax number rather than a Social Security number, and since 2002 , undocumented high school graduates have been allowed to pay in-state tuition at state institutions of higher education, a provision consistent with the federal-level DREAM Act-which was originally cosponsored by US Senator Orrin Hatch, from Utah.

Perhaps the most striking evidence of this different tone came in 2010 with the unveiling of the Utah Compact (www.utahcompact.com). Supported by a broad coalition of business leaders, religious groups, and politicians, the compact was a statement of principles about immigration. It was intended in part to blunt the growing anti-immigrant sentiment that was seeping its way from Arizona into Utah politics and that was accelerated when Arizona state Senator (and member of the Mormon Church) Russell Pearce became the primary sponsor of Arizona's infamous anti-immigrant bill, SB I070. In contrast to the sentiments expressed in Arizona, the principles of the Utah Compact include celebrating the importance of immigrants to Utah's economy, recognizing the integration of immigrants into communities across the state, and opposing policies that unnecessarily separate families. The development of the pact was led by the Salt Lake City Chamber of Commerce, in close collaboration with, among others, the Catholic Diocese and the conservative Sutherland Institute, reflecting a surprising diversity of interests committed to immigrant integration. While the Mormon Church never formally signed the compact, it did issue a formal statement supporting the principles of the compact, describing it as "a responsible approach to the urgent challenge of immigration reform" that is consistent with key principles of the Mormon faith. ${ }^{4}$

The tone set by the Utah Compact suggests an approach one might not associate with the conservative voices representing the state in 
Congress. It is a tone characterized by valuing the "other," recognizing common roots in the region, and trying to develop a civil conversation about the facts. It is this sort of regional culture that helped to set the context for and, arguably, helped facilitate the creation of one of the most impressive collaborative, consensus-based, regional planning initiatives in the country: Envision Utah.

\section{Vision and Voice}

Envision Utah originated from the creation of the Coalition for Utah's Future in I988. The coalition, which included political, business, and civic leaders, came together because of a growing concern about losing population, particularly younger people, to more prosperous states. The economic troubles facing Salt Lake City in that era ended up being quite short-lived; by the early I990s, unemployment had dropped to 3.5 percent and employment growth rates averaged $4-5$ percent a year for four years in a row, driven in part by a technology boom. ${ }^{5}$ Instead of population loss, by mid-decade the primary concerns were around quality-of-life issues, with growing air pollution and rapidly expanding sprawl, which was eating up farmlands and threatening neighboring canyons and mountainland.

Thus, in I995, the coalition began the Envision Utah project, in an effort to address the challenges of population growth and sprawl along the entire Wasatch Front. It was clear from the beginning that for the initiative to have any impact it could not be predicated on the influence of government zoning or regulatory authority-that's just not how Salt Lake rolls. Rather, it had to be deeply rooted in the values of hundreds of organizations and thousands of individuals throughout the region. Thus, the process began with the creation of a hundred-person steering committee representing a wide range of influential business leaders, philanthropists, community leaders, and politicians, and the commissioning of a study of community values related to quality of life. This study ended up identifying two critical values that underpinned future efforts: the importance of Utah's scenic beauty and recreational opportunities; and the deep commitment to being a valued place for raising children and strengthening families (Envision Utah 20I3; Scheer 20I2).

Subsequent Envision Utah efforts included the development of alternative scenarios for long-range development in the region, and a broad public consultation process about the variety of possible future scenarios 
that included more than 2,000 people in fifty public workshops and some 17,500 responses over the Internet and through a mail-in newspaper survey (Envision Utah 20I3). The resulting Quality Growth Strategy was not a detailed land-use plan for the region but a summary of the preferred direction and principles of growth. These included seven clear goals for future development: improving air quality, promoting housing options, creating transportation choices, encouraging water conservation, preserving critical lands, supporting efficient infrastructure, and exploring community development. These principles then became the basis for the development of more detailed implementation plans (for local jurisdictions throughout the region and regional planning bodies) that have extended through to today.

By 2012 , the dean of the University of Utah's School of Architecture and Planning described the impact of the initiative's "remarkable" success in this way:

The Salt Lake metro region has an extensive and rapidly expanding light rail and commuter rail system that is the envy of much more populous regions. The Department of Housing and Urban Development awarded a Salt Lake regional consortium the largest of its highly competitive Sustainable Communities Grants. The two metropolitan planning organizations of the region have cooperated to prepare a long-range transportation plan based on land use aspirations that include higher density. One of the largest "smart growth" planned developments in the U.S. is taking shape on 95,000 acres on Salt Lake's west side. Cities all over the region are developing plans for transit-oriented development and dense town centers, along with the policy and zoning changes needed to support them. City planners from eleven jurisdictions in Salt Lake County have come together to share data, maps, and forecasting information, with the expectation of assembling a coordinated county plan. . . . Most intriguing, data suggest that Salt Lake County is growing with more compact development and a pronounced tendency for denser housing and new jobs to locate near transit throughout the region. (Scheer 2OI 2, 2-3)

During our site visit, informants stressed that there were a number of keys to the success of these regional planning efforts. The first was the ability to tap into values of a high quality of life, and a concern about the legacy being left to children, which was critical for helping people see the importance of long-range planning rather than in-the-moment market-driven development. The second was attention to long-range visions of the future of the region; this helped overcome contemporary divisions that would be exacerbated in discussions of specific projects and helped build a sense of common destiny within the region. Finally, 
in a place with very conservative and generally anti-government norms, it was important that this regional planning process was driven not by government but by a nonprofit, which was in turn driven by business, civic, and community leadership.

In any case, the collaborative, diverse, and consensus-driven process was critical in shaping people's understanding of complex regional processes and building long-term buy-in to a shared vision. It was not about government but about governance-and it drew boundaries around planning that crossed issue silos and gave direction to actors, such as cities, developers and agencies, who still retained their own autonomy and authority. And it was not simply about setting a static plan but about developing the capacities to react to economic and demographic shifts. Indeed, the early reasons for jump-starting the effort changed (from concerns about declining population to concerns associated with population growth), but Envision Utah continued. In short, this was almost the very definition of what we have termed a diverse and dynamic epistemic community. And while the favorable results for growth and equity have many structural and other drivers, certainly this was fertile soil being prepared by Envision Utah.

\section{Making Sense of Salt Lake}

Chapter I offered a frame regarding the key characteristics of a diverse and dynamic epistemic community. The first of those had to do with membership. The remarkable thing in Salt Lake is how widespread participation has been, particularly via the vehicle of Envision Utah. This has been achieved through repeated interactions and long-term communications (including through the media). It is also the case that the LDS Church reinforces norms regarding strong ties to hold the region together-and, interestingly, it also tends to unite non-Mormons into that place identity. Both Mormons and non-Mormons are seen as part of the region's future, and the strong sense of place in the Wasatch Front, along with a cross-cutting and widely held value of preserving the high quality of life in the region, helps bind these diverse constituencies together.

With respect to ways of knowing, however, the LDS Church probably has a narrowing effect on the types of knowledge that are considered legitimate in the region. After all, African Americans were barred from the Mormon priesthood until I978 (White and White I980), and women are still not allowed to be ordained, which arguably reflects 
beliefs that emphasize "distinct gender roles [that restrict] women's contributions, [assign] them to a particular sphere, and [add] to their silence and invisibility" (Cornwall 200I, 262). On the other hand, beliefs and practices of Mormons have played an invaluable role in helping build the visibility of the poor and of immigrants in the region, including those who are undocumented. Envision Utah's work has also been critical in validating the perspectives of ordinary residents in long-range planning processes that can sometimes be dominated in other places by technically sophisticated planning professionals.

One critical gap in the work of Envision Utah has been its tendency to avoid controversy (Scheer 20I2). The group eschewed any stance on an important freeway project that some viewed as sprawl-inducing (or at least sprawl-reinforcing), and it also sidestepped issues raised by a massive redevelopment project undertaken by the LDS Church-one that again seemed to be pushing growth outward, and was therefore at odds with the more compact approach Envision Utah has stressed. This was not a subconscious mistake. Part of the strategy of Envision Utah has been to focus on the long term and stay "above" the day-to-day by downplaying immediate conflicts. Of course, life is made day to day, so one wonders whether Envision Utah can permanently avoid the tough conversations about more difficult topics.

Nonetheless, we don't want to pick too much on what seems to be working. The interconnections of multiple issues-from air quality to housing development to transportation, and so on-within a long-term planning process seems to have helped build and sustain wide engagement of diverse stakeholders in discussions about the region's futureand it is arguably just as dynamic, if not more so, sixteen years after it began. Though there is no guarantee of what the future will bring, the regional planning processes that have evolved in Salt Lake over the past few decades are impressive, and seem to have played some role in creating the conditions for what turns out to have been a relatively strong performance on growth and equity.

\section{SACRAMENTO}

Sacramento is another region where planning processes have been important for shaping the region's trajectory. Though sometimes derisively referred to as Cowtown-the unsophisticated inland kid sister of California's flashier coastal cities-Sacramento, the state's capital, 


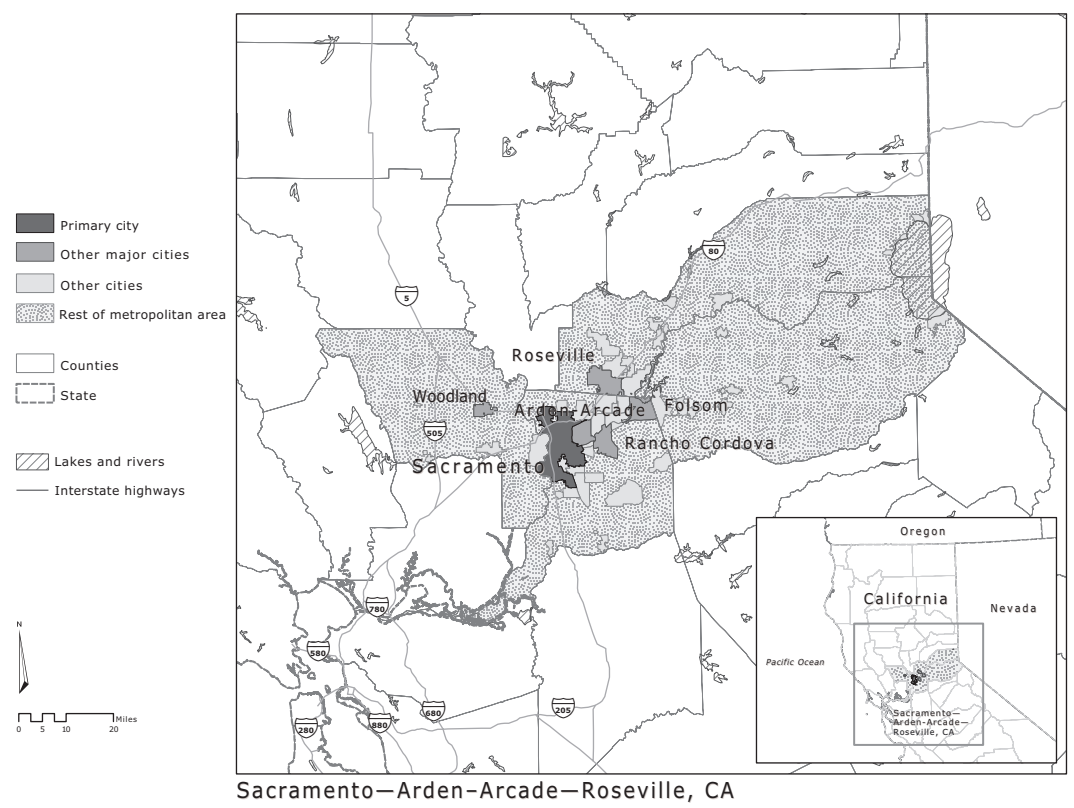

MAP 4.2. Sacramento Region.

is now a dynamic region of over two million. ${ }^{6}$ Sacramento's economy has traditionally drawn stability from its large public sector, anchored in middle-wage jobs. However, the closure of four large military bases in the late I980s and early I990s altered the structure of the region both economically and socially. Sacramento soon realized that weathering major economic shifts requires a broad-based strategy underpinned by a regional vision-and much of the last decade has included substantial regional initiatives intended to define and achieve that vision.

The results have been palpable. While the I990s were not nearly as prosperous as the I980s, the region's performance during the most recent decade demonstrated a substantial rebound. These results in the 2000 s were shaped by a prominent and multifaceted "smart growth" planning process that helped create a new norm of regional collaboration, with an important role played by the local council of governments. Through its ups and downs (and ups once again), Sacramento has learned-and can teach—some essential lessons about the value of participatory regional planning. 


\section{Stumbling and Bouncing Back}

Sacramento's patterns of growth and equity over the past thirty years would be the envy of many regions. The region nearly doubled in population between 1980 and 2010 , and job growth in the I980s was over 50 percent, with another 26 percent of growth in the I990s. Earnings per job have increased consistently as well-growing 7 percent in the I980s, I4 percent in the I990s, and 7 percent in the 2000 s. Overall patterns of equity, at least as measured by our $80 / 20$ household income ratio, actually improved in the I980s. Though inequality has increased in recent decades, as it did in nearly all regions in the United States, Sacramento's increases in inequality and poverty have been substantially smaller than the average in the West and in the country as a whole.

Some of Sacramento's success can be attributed to structural ingredients that generally help to shape equitable growth patterns: a strong public sector, providing a sizable and relatively stable number of middleclass jobs; a respected community college system, offering mobility and training to a diverse cross-section of students; and a near-the-Bay location that has proved attractive to some firms wishing to relocate to slightly cheaper environs. In addition to being California's capital and so hosting a range of state agencies, Sacramento's public-sector employment has also been anchored by a strong military presence.

Until the rounds of base closures in the late I980s and I990s, Sacramento was home to four large military bases: McClellan Air Force Base, Mather Airfield, Sacramento Army Depot, and Beale Air Force Base. McClellan was the largest of the group, dedicated to logistics and the maintenance of military aircraft. At its peak it employed over 22,000 workers (DuBois 20II). An ecosystem of military contractors and related industries grew to support the local industry, and a segment of these firms is still in operation today, including Aerojet, which designs, builds, and tests rocket engines (Benner and Pastor 2012). And since housing was affordable, unlike in California's high-cost coastal areas, the military and public-sector employees could buy homes, sink roots, and constitute the base for a broad middle class.

Housing and real estate prices were also key to attracting high-tech firms seeking affordable spaces for their operations and quality of life for their employees. Throughout the I980s and I990s, the region became an outpost for Silicon Valley firms, such as Hewlett Packard, Apple, and Intel. Beyond lower costs, the region's seismic stability attracted firms looking to relocate away from the earthquake-prone environments of 
the San Francisco Bay Area. ${ }^{7}$ These industries contributed to a more egalitarian growth pattern by providing well-paying jobs for low- and middle-skilled workers. The defense industry, in particular, helped create a strong African American middle class in the region. At the close of the I 980 os, average annual wages were relatively high, at $\$ 45,800$ (inflation-adjusted to 20 Io dollars), and unemployment was low, at 4.9 percent.

However, in the I990s, the economy downshifted, partly due to post-Cold War defense spending cuts and partly due to the rise of lowwage sectors. Between I988 and I995, three of Sacramento's military bases closed, and California's share of defense contract expenditures fell from 24 percent of the nation's total to I4 percent in 2003 (Freedman and Ransdell 2005). Simultaneously, the region shifted toward a service-based economy anchored in low-wage jobs. Call centers, backoffice operations, and financial processing firms proliferated in the area, drawn by the region's fiber optic infrastructure, the result of early government investment. These jobs partially supplanted those lost from the defense scale-back, but with less of a middle-led thrust. Jobs in highwage industries actually declined by I 4 percent in the 2000 s, while lowwage sectors grew by 8 percent, and overall, the share of employment in low-wage sectors grew from 25 percent in 1990 to 30 percent in $20 \mathrm{IO}$. Meanwhile, African Americans and Latinos trail whites to a significant degree, with household incomes that are 63 and 73 percent of those of whites, respectively.

Yet a culture of collaboration in the region, which rose to prominence in the base-closure process, has probably helped mitigate some of the worst negative trends and build a foundation for more positive trajectories. During the base-closure process, elected officials and organizations worked across many levels of government to secure new economic development opportunities in advance of base closings and devised a plan for reskilling and repurposing the workforce, which was led by the Sacramento Employment and Training Agency. One prominent example of the success of these coordinated efforts was an initiative, spearheaded by the Sacramento Area Commerce and Trade Organization, to find new tenants for the Army Depot facility. The region was able to entice Packard Bell to relocate from its Southern California location in I995, prompted in part by damage to its Southern California facilities caused by the 1994 Northridge earthquake (Lesher and Leeds 1997).

The decentering of the economy away from an anchor industry has nudged many organizations, local governments, and businesses 
toward the development of intersectoral networks and collaboration. Sacramento's increasing size and diversity-in 2010, it was home to nearly 2.I 5 million residents, nearly half of whom were people of color-have also contributed to the growth of new interests and alignments. Simply put, in a growing region with no stars-whether major corporations, large-scale philanthropies, or big-name individualspeople have more often had to work together to solve complex problems rather than depending on single leaders or individuals to pave the way. Through careful and thoughtful regional planning processes, Sacramento's knowledge networks, leadership structures, and decisionmaking processes are evolving and embracing the idea of more inclusive and more sustainable economic growth.

\section{Planning the Future}

In the absence of a pillar industry, a major philanthropic force, or a strong social movement for justice, Sacramento's regional leadership has historically been a "roving" one (a term used by one of our interviewees). Rather than individuals or institutions acting as regional conveners, collaborations tend to form around single campaigns, and the constellation of actors and interests involved is determined by the issue at hand. While this model can have its upsides-mainly that regional collaboration is not dependent on one leader or entity and thus can endure through personnel turnover-it also means that regional collaboration has no permanent home.

Yet, over the last decade in particular, signs of more institutionalized regional collaboration have emerged in an effort to plan for a more sustainable future. One key initiative has been the regional Blueprint process, a public sector-led "smart growth" planning initiative that merges some of the newest thinking around land use and development patterns. Indeed, the origins of the Blueprint are rooted in the problems wrought by earlier patterns of development. Through the I980s, I990s, and early 2000s, Sacramento's population and employment growth were accompanied by low-density housing development sprawling outward from the urban core. This pattern led to a severe imbalance between jobs and housing, creating high levels of car dependence and increased air pollution associated with vehicle emissions (McKeever 20II). Indeed, it was estimated that if Sacramento were to continue this pattern of unabated and rapid sprawl, which was swallowing agricultural land, the region's traffic congestion would increase by 50 percent by 2050 (Faust and Cogan 2010). 
Unlike Salt Lake, in which the largely anti-government sentiment meant that regional planning was best launched from the nonprofit sector, in Sacramento the metropolitan planning organization, SACOG (Sacramento Area Council of Governments, consisting of twenty-two cities and six counties), ${ }^{8}$ stepped up to convene regional stakeholders and address the problems arising from sprawling development patterns. Starting in 2002, SACOG began a long-range regional planning process to engage residents in helping shape how their communities grow, through a common vision for land use and transportation infrastructure through 2050 . As one might imagine in a relatively diverse region, there were many opposing views about the future of Sacramento. The first main conflict was between environmentalists and builders. Environmentalists were concerned about the continued negative impact of unbridled sprawl on the region's environment and air quality, while builders were concerned about regulations that would jeopardize their livelihoods by limiting development.

A second main conflict was between urban, suburban, and rural jurisdictions. This is a common challenge in regional planning because different geographies have different economies and different landuse and transportation needs. Moreover, there are power imbalances between large urban cores and smaller rural towns, and resource allocation can be very contentious. So, not only were there long-standing interjurisdictional tensions around power and resources, all the cities and counties were concerned that SACOG's long-term regional vision and plan would overlook or even hinder the ability of each city and county to address its community's unique needs.

To facilitate collaboration and work through these deeply entrenched and often heated conflicts, SACOG took a simple yet rarely used approach: focus the conversation on the facts instead of ideology-or, as SACOG executive director Mike McKeever put it in our interview with him, "the science behind how the region operates." In short, as part of visioning for the long-term regional plan, SACOG promoted dialogue about facts to develop a "common knowledge base"-the heart of epistemic communities-rather than fights about beliefs and opinions that were not likely to change.

Using the Envision Utah model of scenario planning, SACOG spearheaded a process of comparing a base case scenario of sprawling and uncontrolled urbanization-the status quo-against other scenarios designed to promote denser development and expanded mass transit. To help with the community-outreach piece of the Blueprint process, 
SACOG partnered with Valley Vision, a nonprofit organization committed to building civic engagement while addressing regional issues. SACOG was responsible for the technical and land-use planning work, while Valley Vision led the outreach effort (Faust and Cogan 2010). Throughout the region, SACOG held more than thirty neighborhoodlevel workshops (involving more than I, ০oo community members) to discuss development scenarios. Following this, discussions were held in five of the six counties in SACOG's jurisdiction, and more than I,400 people participated in a final regional forum on April 30, 2004.

Part of presenting the facts was providing statistics about the region. SACOG profiled the region's projected employment and population growth and other demographic information to begin a conversation about expected growth in the future. Working with groups like the Urban Land Institute and the Metro Chamber, SACOG also did a survey of housing choice preferences and demonstrated the demand for more multi-family options-which served as helpful market information for developers and builders by demonstrating the existing and future market for denser development. 9

The other, and perhaps more important, data piece for the purpose of bringing diverse interests and geographies together was public opinion polling throughout the region. SACOG commissioned Richard Wirthlin, a well-respected polling consultant to Ronald Reagan, to test the public's attitudes toward growth and specific planning principles, such as mixed land use, walkable neighborhoods, open-space preservation, and transportation choice. He found that the region's residents were concerned about the potential downsides of growth, such as worse traffic and air quality, and that they supported regional planning and its related principles. These results were shared at an Elected Officials Summit, a large gathering of 80 local officials representing city councils and county boards across the region. At the summit, officials were asked a series of questions on regional growth and the Blueprint via live polling, and these results showed strong support for the plan's growthmanagement approach (SACOG 2004).

In the end, through a long and intentional process of community engagement and consensus building, the Blueprint developed a map showing different types of growth that constituents wanted to occur by 2050 , guided by seven principles: housing choice and diversity, use of existing assets, compact development, natural resources conservation, high-quality design, mixed-use development, and transportation choices. As one interviewee stated, at the beginning of the Blueprint 
process in 2003 , these principles were extremely controversial; by the final vote in $\mathbf{2 0 0 4}$, they were just common sense-or, more formally put, new norms.

The planning effort was so innovative and collaborative that it would eventually garner national awards for both the outcome and the process that produced it. The Blueprint process has also served as a template for other regional planning efforts and influenced both state and national policy. In California, the Blueprint informed the development of Senate Bill 375, which sets regional greenhouse gas reduction goals, emphasizing the role of urban and regional planning strategies to curb pollution. Under the plan, regional planning bodies are required to develop a Sustainable Communities Strategy as a part of their regional transportation plan (Eaken, Horner, and Ohland 20I2). It seems no coincidence that the author of the bill, Senator Darrell Steinberg, is a long-time Sacramento resident and former member of the city council. The Blueprint process also informed the development of-and plans stemming from-the US Department of Housing and Urban Development's Sustainable Communities Initiative, which provides grants to support sustainable local and regional planning efforts that integrate housing and transportation plans with land-use planning to encourage sustainable development (Chapple and Mattiuzzi 20I3; ISC 20I2).

From conflict to collaboration, the Blueprint process is a striking example of using the planning process to generate an epistemic community-a network with shared mechanisms of knowledge generation and knowledge integration - and to then use that newly developed, shared knowledge in decision-making processes that can create new cultural norms and further the common good. Through the process, a strong sense of regionalism emerged; communities and sectors began to view themselves as part of a broader regional puzzle, rather than stand-alone pieces.

\section{Coming Up Short}

Of course, every process has its shortcomings. The biggest gap in the Blueprint was the relative lack of attention to social equity. Equity advocates note three broad areas for improvement: better incorporation of disadvantaged communities in planning; the creation of more equityfocused planning goals; and the need to develop specific equity metrics to track performance.

Realizing the need to do better on equity-and also prodded by state law-SACOG is taking steps to incorporate equity metrics and 
goals, most recently within the context of their Sustainable Community Strategy - an update to the Blueprint plan. One chapter of the plan, "Equity and Choice," outlines strategies for increasing outreach, understanding affected communities, and planning for equity outcomes. In terms of outreach, SACOG has turned an eye toward refining its outreach efforts, particularly toward the environmental justice community, as well as other disadvantaged groups like new immigrants and those with limited English-speaking abilities. On the data and goals front, SACOG is working to define and map vulnerable areas and environmental justice communities, including their transportation and housing options. These baseline metrics contributed to the development of equity-related performance metrics in the plan (SACOG 20I2). SACOG received feedback from several local organizations, including the Center for Regional Change at the University of California, Davis (http:// regionalchange.ucdavis.edu)—an equity-focused research center-and the Coalition on Regional Equity (CORE).

While SACOG could have done better at including equity voices in its first iterations of the Blueprint, it is also the case that the current fragmentation of equity groups and interests within the region presents a challenge. Sacramento's equity advocates include several strong issuebased groups representing various interests-from environmental justice communities to housing and human rights advocates to regional equity researchers-but there is no specific regional coalition and no shared forum for developing policy and organizing strategies around equity.

For a few years, CORE served as the focal point for organizing the region's groups on issues of equitable development, having been formed in 2007 after a number of member organizations successfully fought for one of the nation's most progressive inclusionary housing ordinances. The group went on to shine a light on residential segregation and health disparities, and the need for affordable housing and better access to healthy food. But while CORE's work was impactful, it was also shortlived, as the group dissolved over internal tensions in 20I3. The nature of the tensions was actually quite classic: groups more oriented around social-change advocacy were interested in stronger action, while groups more enmeshed in the delivery of social services and housing development were worried about being too explicitly political.

In any case, the growing focus on equity, made more explicit through the Sustainable Communities Strategy process, serves as another step toward building a diverse and dynamic knowledge-sharing community in Sacramento. While the Blueprint process initially came up a bit short 
with regard to including equity concerns and equity actors, there is an iterative dynamism in the process-it has what one observer called a "rinse-wash-repeat" nature-and the architects of the Blueprint themselves have recognized the need to build in more metrics and goals for social equity (Pastor and Benner 2OII, IO2). This is of course more difficult when the equity actors are a bit fragmented, but this just presents another challenge.

\section{Synthesizing Sacramento}

Recall that our broad characteristics of diverse epistemic communities include their membership, the way they create ties that bind, the ways of knowing that are viewed as valid, the range of outcomes under discussion, and the ability to adapt over time. This historical trajectory is key, particularly since a longer set of repeated interactions can set a regional epistemic community on a better and more stable path. However, in Sacramento, the emergence of a diverse and dynamic process is relatively new, and it was largely jump-started by a formal planning mechanism.

Until the I990s, Sacramento's regional economy and pattern of reasonably equitable development stemmed largely from a healthy public sector and a strong defense industry-so equitable outcomes were partially a byproduct of an economy producing middle-wage jobs, many of which employed people of color. With declines in defense spending in the I990s and the appearance of the consequences of rapid and poorly planned growth, particularly sprawl and environmental degradation, the region's calling card of livability, including clean air, good jobs, affordable housing, and sensible commute times, was under threat.

The largest and most comprehensive response to this challenge was the Blueprint process, a regional planning effort advanced by SACOG. Generating a vision for regional growth required deep outreach, the use of data to cut through ideology and tensions (i.e., new "ways of knowing"), and a focus on integrating feedback and refining the plan to create buy-in. Through this process of convening, knowledge sharing, and regional goal setting, Sacramento has experienced an emergence of a form of multi-sector and multi-goal regional collaboration containing many of the elements of what could be a diverse and dynamic epistemic community in the future. Given the rather modest expectations that planners would be able to do any of this-as evidenced by the jokes at the beginning of this chapter-it is all the more remarkable that SACOG has come close. 


\section{PLANNING FOR PROGRESS}

Urban and regional planning in the United States can sometimes seem to involve a mind-numbing focus on the micro-details of zoning and regulations. How many parking spots should be required for each new housing unit? What setback distance from the street is optimal for a new commercial development? What density of housing and commercial space is appropriate for particular neighborhoods? How high can new buildings rise above street level? How quickly can we end this conversation?

Communicative planning aims a bit higher. It understands that though technical details may be critically important for building better neighborhoods, cities, and regions, the most important topics involve the political processes of regional development and the role of participation in planning processes. And, as we have argued here using the cases of Salt Lake City and Sacramento, such planning can actually go beyond the technical specifications of the built environment and encourage a dialogue about norms and values and how they should shape the communities and regions in which we live.

This is exactly the stuff of building diverse and dynamic epistemic communities-and as we suggest in subsequent chapters, it can actually occur in ways that are more diffuse and multi-sector than is generally envisioned in the literature on "communicative rationality." On the other hand, sometimes planners can play an important role-and that was certainly the case in both the regions reviewed here. In Salt Lake City, Envision Utah, and in Sacramento, SACOG, managed to create a new conversation that has facilitated the emergence of a common understanding about each region's destiny.

There are three features of these cases-each rooted in regional planning efforts-that seem particularly important to stress here, and that link back to our efforts to elaborate the characteristics of diverse and dynamic epistemic communities. The first has to do with the time frame of the visioning processes, and the associated ability to maintain a dynamism of interaction over time. In both cases, discussions emphasized both long-range trends that were creating current regional challenges, and long-term visions of what future regional development patterns might look like. This long-range perspective helps regional stakeholders move beyond their immediate needs and interests, and be more open to thinking about different choices and options of future development patterns. It also enabled processes of implementation and monitoring 
to follow on from the initial visioning process, allowing the members of the epistemic community to adjust to changes and emerging challenges. Of course, setting aside the day-to-day to downplay critical tensions can actually work against long-term goals-conflicts still simmer. The initial emphasis on a longer time frame can also break down entrenched conflicts and help stakeholders with seemingly opposing interests understand that they may have a lot more in common than is initially apparent.

A second key feature of these collaborative long-range planning efforts was the recognition of the legitimacy of others' viewpoints and interests. All too often, in policy debates or political campaigns, the focus is on gaining a majority so that one group's preferences can prevail and then be imposed on the minority. But in these comprehensive planning processes, there was an effort to include all residents of the region, if not in the planning process, at least in the plan. It is that recognition of the legitimacy of "the other"-whether that "other" is defined by political ideology, economic interests, race, or any other dimension-that facilitates the acceptance of diversity that we think is crucial to forging a common destiny.

Finally, though tensions emerged in both regions around processes of long-term planning, the parties involved remained committed to continued engagement. Through processes of information sharing and vision setting, residents and regional leaders came to see new ways in which their futures were bound together. This sense of a common regional destiny-despite differences in interests, values, and experienceshelped each region develop coordinated responses to regional challenges, and developed new ties that bound different interests in the region together. There are certainly limits to the levels of involvement in these deliberate planning processes, with a fragmented constituency advocating for social equity still characterizing both regions. But the level of broad participation was substantial, and this helped create a new sense of the region and of the role for regional place-making. 